Société d'histoire de la révolution de 1848 et des

révolutions du XIXe siècle

49 | 2014

1814-1815. Expériences de la discontinuité

\title{
Alain VERGNIOUX, George Sand et l'éducation populaire. Leroux, Nadaud, Perdiguier
}

Paris, Lambert-Lucas, 2014, 122 p. ISBN : 978-2-35935-115-6. 15 euros.

\section{Carole Christen}

\section{(2) OpenEdition}

Journals

Édition électronique

URL : http://journals.openedition.org/rh19/4770

DOI : $10.4000 /$ rh 19.4770

ISSN : $1777-5329$

Éditeur

La Société de 1848

\section{Édition imprimée}

Date de publication : 1 décembre 2014

Pagination : 221-223

ISSN : 1265-1354

\section{Référence électronique}

Carole Christen, «Alain VERGNIOUX, George Sand et l'éducation populaire. Leroux, Nadaud, Perdiguier », Revue d'histoire du XIXe siècle [En ligne], 49 | 2014, mis en ligne le 01 décembre 2014, consulté le 22 septembre 2020. URL : http://journals.openedition.org/rh19/4770 ; DOI : https://doi.org/10.4000/ rh19.4770

Ce document a été généré automatiquement le 22 septembre 2020.

Tous droits réservés 


\title{
Alain VERGNIOUX, George Sand et l'éducation populaire. Leroux, Nadaud, Perdiguier
}

Paris, Lambert-Lucas, 2014, 122 p. ISBN : 978-2-35935-115-6. 15 euros.

\author{
Carole Christen
}

\section{RÉFÉRENCE}

Alain VERGNIOUX, George Sand et l'éducation populaire. Leroux, Nadaud, Perdiguier, Paris, Lambert-Lucas, 2014, 122 p. ISBN : 978-2-35935-115-6. 15 euros.

Dans ce bref essai, Alain Vergnioux - docteur en philosophie et professeur émérite en science de l'éducation à l'université de Caen -, spécialiste de la philosophie de l'éducation, s'intéresse à la conception républicaine, révolutionnaire et socialiste de l'« école du peuple » telle que George Sand (1804-1876) l'envisageait et aux parcours de trois « intellectuels » issus des classes laborieuses qu'elle a successivement rencontrés en 1835, 1840 et 1871 : Pierre Leroux (1797-1871), Agricol Perdiguier (1805-1875) et Martin Nadaud (1815-1898).

2 L'ouvrage s'organise en cinq chapitres. Le premier présente une synthèse très générale de la genèse de l'éducation populaire et de la mise en place, à partir de la Restauration et jusqu'à la fin du Second Empire, des premières expériences de scolarisation élémentaire, de diffusion des connaissances, de cours du soir destinés aux adultes. On regrette l'absence de contextualisation et présentation des quelques exemples et acteurs cités, et par là celle de la prise en compte des évolutions socio-économiques et politiques de la période évoquée qui influencent fortement le développement de l'éducation populaire. Le deuxième chapitre porte sur Agricol Perdiguier, compagnon de France, " ouvrier poète ", élu député républicain à l'Assemblée constituante en 1848 et contraint à l'exil après le coup d'État du 2 décembre 1851. Perdiguier entretient une relation épistolaire avec George Sand pendant plus de trente ans. Elle le soutient 
financièrement dans la diffusion de son ouvrage Le livre du compagnonnage et elle sollicite ses conseils pour son roman Le Compagnon du Tour de France. Perdiguier cherche à diffuser la formation professionnelle (il donne des cours de dessin le soir) et la lecture. Le contenu de sa bibliothèque et de celle qu'il envisage pour tous les ouvriers témoignent du rôle déterminant qu'il accorde à l'instruction, à la culture et aux connaissances en général dans l'émancipation sociale et politique du peuple. Le troisième chapitre retrace, à partir du récit autobiographie Mémoire de Léonard, ancien garçon maçon, le parcours de Martin Nadaud, son ascension sociale et sa carrière politique grâce à l'instruction. À la fin de la Restauration il commence son apprentissage d'ouvrier maçon à Paris. Témoin de la révolution de 1830, il s'engage dans les mouvements de revendications républicaines et ouvrières tout en suivant quelques cours du soir, avant de donner ses propres cours du soir aux jeunes ouvriers. On aurait aimé en savoir davantage sur ses liens avec Georges Sand. Quand se sont-ils rencontrés ? Quels ont été leurs échanges ? Le quatrième chapitre est consacré à Pierre Leroux. Contraint d'abandonner de brillantes études - il est reçu à l'École polytechnique - pour subvenir aux besoins de sa famille, il devient ouvrier typographe et participe à la fondation de plusieurs journaux et revues - dont La Revue indépendante et La Revue sociale avec George Sand. Son activité éditoriale lui permet de diffuser ses idées républicaines et socialistes et sa philosophie (la doctrine du progrès et de la perfectibilité) de laquelle découle son programme d'éducation globale que l'État devra prendre en charge et contrôler. Il entretient avec George Sand une longue amitié : elle l'aide lui aussi matériellement et la philosophie de Leroux influence ses romans. Le cinquième et dernier chapitre porte sur l'omniprésence de la question de l'éducation dans l'œuvre de George Sand. Son importance dans la voie de l'émancipation et la nécessité de la diffuser dans toutes les classes sociales, pour les deux sexes, en ville et à la campagne, traversent ses romans, ses contes et ses pièces de théâtre. Mais elle ne prend pas part aux débats sur l'instruction primaire généralisée ni aux projets d'école publique de ses amis républicains. Critique envers les méthodes pédagogiques de son époque, elle place l'enfant au centre de sa pédagogie où la lecture et la nature jouent un rôle essentiel.

3 L'auteur cite fréquemment des extraits de textes ou de correspondance des quatre auteurs étudiés mais utilise aussi très souvent des ouvrages de seconde main, sans vérifier les informations qui sont parfois erronées. Dans la bibliographie en fin d'ouvrage, les travaux historiques (ceux cités sont anciens, les études récentes n'y figurent pas) ne sont pas différenciés des sources imprimées.

4 Cet ouvrage qui se proposait « de combler un manque» (p. 8) ne tient pas toutes ses promesses, il a néanmoins le mérite de faire une brève synthèse sur les destins et les œuvres d'une femme de lettres et de trois ouvriers militants républicains qui se sont intéressés à la question de l'éducation populaire dans le premier XIX ${ }^{\mathrm{e}}$ siècle, soulignant ainsi son importance, et il doit inciter les historiens du dix-neuvième siècle à s'y intéresser davantage. 